\title{
RNA induced enhancement of a simple discrimination task
}

ROBERT G. GIBBY, DAVID G. CROUGH, and SAMUEL J. THIOS, Veterans Administration Hospital, Richmond, Virginia

The applicability of a sinple light-dark discrimination task to the study of RNA induced behavioral effects was investigated. Significant results with $R N A$ extracted from trained donors using the cold phenol method support the value of this task in future $R N A$ investigations.

Investigators of RNA induced learning facilitation have employed a wide variety of tasks. Approach to a food cup (Babich, Jacobson, Bubash, \& Jacobson, 1965), habituation of the startle response (Ungar \& Oceguera-Navarro, 1965) and wireclimbing (Gibby \& Crough, 1967) are some of the tasks previously investigated. Criticism of these studies as well as investigations employing other tasks is that frequently responses cannot be as objectively scored as would be desirable. An even more valid criticism is that results often cannot be replicated. In order to develop a standardized procedure which overcomes these objections several pilot studies have been completed at McGuire VA Hospital. A light-dark discrimination task has shown the most promise in these preliminary studies.

Other investigators, Fjerdingstad, Nissen, \& Roigaard-Petersen (1965), used a two-alley runway with a water deliverer placed under a houselight at one end and a single bulb placed above each response platform at the opposite end of the apparatus. Ss received a $0.1 \mathrm{ml}$ water reinforcement after each return from the response platform of the illuminated alley. Illumination in the alleys was changed in random order. Rats injected intracisternally with trained RNA performed better than naive RNA or anesthetized controls. These results were confirmed by the same authors in a subsequent experiment (Nissen, Roigaard-Peterson, \& Fjerdingstad, 1965). Negative results, however, with a foodrewarded light-dark discrimination task have been reported by Hoffman, Steward, \& Bhagavan (1967). Either of two procedural differences might account for these conflicting results: (1) amount of donor training and (2) method of injection. It is the purpose of this experiment to further investigate whether RNA extracted from rats trained on a food reinforced light-dark discrimination task will facilitate acquisition of this task in naive animals.

\section{SUBJECTS}

The Ss were 80 male Wistar rats each weighing between $170-190$ $g$ at the time of testing. These formed two major groups: the donor $(\mathrm{N}=32)$ and the recipient $(\mathrm{N}=48)$ groups. All recipient groups compared consisted of littermates. The donor group was divided into two groups of 16 . One of these groups was trained on a shock avoidance task and the other group was trained on a light-dark discrimination task. The recipient rats were divided into six groups of eitght $\mathrm{Ss}$ each and were injected and run as follows:

Injection

RNA from donors trained on light-dark discrimination

RNA from donors trained on shock avoidance

Reagent blank

RNA from donors trained on shock avoidance

RNA from donors trained on light-dark discrimination

Reagent blank
Test

Code

Light-dark

discrimination

Light dark

discrimination

Light-dark

discrimination

Shock-avoidance

SASA

Shock-avoidance

DSA

Shock-avoidance

RBSA
Groups DSA and SAD were employed to control for possible activating effects of trained RNA while groups RBD and RBSA were employed as conventional reagent blank controls. APPARATUS

The light-dark discrimination apparatus was a double alley maze consisting of a start box and a run section (each $6 \times 8 \times 10$ in.) and two parallel goal boxes (each $12 \times 4 \times 10 \mathrm{in}$.). The start, run, and goal sections were separated by Plexiglas guillotine doors. Located above the goal entrances was a $2 \times 8$ in. piece of translucent white plastic. Behind the plastic, over each entrance, was a standard (manually operated) flashlight bulb. The entire apparatus was painted flat black. For training and testing the experimental room was darkened.

The shock apparatus consisted of a Foringer small animal conditioning chamber with appropriate automatic programming and recording equipment.

\section{PROCEDURE}

All donor rats were accommodated to the apparatus and handling by being placed in the appropriate training device (later used as test apparatus) for a period of $10 \mathrm{~min}$ each day for three days before training began. All doors were removed from the light-dark discrimination box and $S s$ were allowed to explore freely. Immediately after each period, each $S$ was given $15 \mathrm{~min}$ access to a feeding cup filled with $45 \mathrm{mg}$ Noyes pellets in his home cage. During training each $S$ in the shock avoidance group received 30 trials daily in the Foringer apparatus according to a schedule developed by Gibby (1965). Each $S$ in the light-dark discrimination group received 30 trials daily as follows:

(1) Light turned on over either right or left alley in random order

(2) Guillotine doors immediately opened

(3) Doors closed upon S's entry into either correct or incorrect goal box

(4) Fifteen sec delay, then $S$ returned to start box

(5) Steps $1-4$ repeated

(6) If $S$ did not enter either goal box within $15 \mathrm{sec}$ after opening the guillotine doors, the doors were lowered, rat returned to start area, and the next trial was begun.

Upon reaching a criterion of 26 correct trials per day for three consecutive days, animals in groups DD and DSA were sacrificed by decapitation. Animals in Groups SASA and SAD were similarly sacrificed upon reaching a criterion of over 26 correct responses for a three day period. The cold phenol extraction procedure employed was that described by Babich et al (1965). A reagent blank was prepared simultaneously.

Recipients in each group were injected IP with the appropriate extract and tested under blind conditions at 12,36, and $48 \mathrm{~h}$ after injection. The testing procedure for all recipients was the same as that utilized in the training procedures.

\section{RESULTS AND DISCUSSION}

To remove possible effects of activity on performance on the light-dark discrimination task, difference scores were found for each $S$ for each of the three test days. The number of incorrect responses was subtracted from the number of correct responses to determine this score. For each day the common median of the scores in the three groups was obtained. Scores above this median were assigned a score of one and scores below this median were assigned a score of zero. A Cochran $\mathrm{Q}$ comparing groups DD, SAD, and RBD was calculated for each daily test period. Significant differences among the groups were found on Day $1(Q=5.33$, $\mathrm{p}<.05,1$-tail). There were two Ss with scores exceeding the common median in each of Groups SAD and RBD, and six Ss with scores exceeding this median in Group DD. Performance increased for all groups over the three test periods and no significant differences were found on Days 2 or $3(Q s=3.50$ and .67 , ps > .05, 1-tail).

For Ss in the three recipient groups tested on shock avoidance (Groups DSA, SASA, RBSA), the number of correct avoidance 
responses was obtained for each $S$ on each of the three daily test periods. These data, analyzed by means of the Friedman test (Siegel, 1956), yielded no significant groups differences on any of the three test periods ( $p>.05$ in each instance). Thus, the shock avoidance task provided no evidence that this active-avoidance task was transferred. Some success, however, has been found with a passive-avoidance task (Gay \& Raphelson, 1967). It may be that due to the wide variety of responses available in the active-avoidance procer ure (e.g., crouching in corner, biting grid), that bar-pressing is not necessarily the response of primary intensity.

From the obtained results it may be concluded that: (1) When tested on a light-dark discrimination task, those Ss receiving RNA from donor Ss trained on that task performed significantly better than those Ss receiving RNA from donor Ss trained on a shock avoidance task and those $S s$ receiving a reagent blank injection. (2) When tested on a shock avoidance task, Ss receiving RNA from donor Ss trained on that task did not differ significantly in performance from Ss receiving RNA from Ss trained on a light-dark discrimination task or from Ss receiving a reagent blank injection.

The results of this investigation demonstrate the potential applicability of a simple light-dark discrimination task in the study of RNA induced enhancement effects. Currently, a replication of this study is in progress.

\section{REFERENCES}

BABICH, F. R., JACOBSON, A. L., BUBASH, S., \& JACOBSON, A. Transfer of a response to naive rats by injection of ribonucleic acid extracted from trained rats. Science, 1965, 149, 656-657.

FJERDINGSTAD, E. J., NISSEN, T., \& ROIGAARD-PETERSEN, H. H. Effect of ribonucleic acid (RNA) extracted from the brain of trained animals on the learning of rats. Scandinavian Journal of Psychology, 1965, $6,1-6$.

GAY, R., \& RAPHELSON, A. "Transfer of learning" by injection of brain RNA: A replication. Psychonomic Science, 1967, 8, 369-370.

GIBBY, R. G., \& CROUGH, D. C. RNA induced enhancement of wire climbing in the rat. Psychonomic Science, 1967, 9, 413-414.

GIBBY, R. G., Sr., GIBBY, R. G., Jr., KISH, G. B., \& THEOLOGUS, G. C. Enhancement of avoidance learning by strychnine sulphate. Psychological Reports, 1965, 17, 123-126.

HOFFMANN, R. F., STEWART, C. N., \& BHAGAVAN, H. N. Failure to transfer a learned response in rats using a brain extract containing RNA. Psychonomic Science, 1967, 9, 151-152.

NISSEN, T., ROIGAARD.PETERSEN, H. H., \& FJERDINGSTAD, E. J. Effect of ribonucleic acid (RNA) extracted from the brain of trained animals on leaming in rats. Scandinavian Journal of Psychology, 1965, 6, 265-272.

SIEGEL, S. Nonparametric statistics. New York: McGraw-Hill, 1956.

SOLYOM, L., BEAULIEU, C., \& ENESCO, H. E. The effect of RNA on the operant conditioned behavior of white rats. Psychonomic Science, 1966, 6, 341-342.

UNGAR, C., \& OCEGUERA-NAVARRO, G. Transfer of habituation by material extracted from brain. Nature, 1965, 207, 301.302. 